\title{
Xray Tomographic Microscopic Studies a Resin Embedded Paint Sample from a Mechanical Failing Area in Floor Tiles of The Art of Painting by Johannes Vermeer (1632-1675).
}

\author{
Jaap J. Boon *, Elke Oberthaler **, Ester S.B. Ferreira ***, Federica Marone **** and \\ Marco Stampanoni ****. \\ * FOM Institute AMOLF, Science Park 104, 1098XG, Amsterdam NL (boon@amolf.nl) \\ ** Kunsthistorisches Museum (KHM), Vienna, Austria. \\ *** SIK-ISEA, Zollikerstrasse 32, 8032 Zürich, CH. \\ **** TOMCAT, Swiss Light Source, Paul Scherrer Institute, Villigen, CH.
}

The condition of The Art of Painting by Johannes Vermeer painted c. 1667 is now considered too fragile for traveling exhibition and required further investigation into the causes of the paint loss [1]. Samples were taken from a fragile green drapery, the white tile floor and close to the rim to investigate the buildup and composition of the ground and paint layers. Various types of microscopy i.e. Light Microscopy, imaging FTIR microscopy, Raman microscopy, F-SEM and SEM-EDX-mapping were performed on hand polished sections. The flaking paint loss from the white floor was also investigated with Xray tomographic microscopy.

The white floor is build up with two paint layer of lead white on a coarse granular ground. The lower paint layer is a so-called Dutch stack lead white with larger up to 10 micron lead white particles in a 1 micron sized lead white matrix. Surprisingly, Vermeer used a unique formula for the surface paint where the particle size is $50-100 \mathrm{~nm}$. He uses oblong ellipsoid bone black particles ( 8 microns long) to render the bluish black marbling. The aged paint binder consists now of a lead coordinated halatopolymer of C9diacids with palmitic and stearic acid. In cross section, funnel formed cracks, large age cracks and conchoidal crack were observed apart from horizontal crack below the surface paint. The conchoidal Wallner line cracks suggest a glass or enamel like behavior of the aged paint. SEM-BSE shows that materials containing potassium and sulfates were transported through the deep age crack from bottom to the surface. Potassium lead sulfate (Palmierite) have reacted with lead soaps or lead white pigment on the surface forming elongated aggregates (up to 50 micron long) and also have filled up the craquelure.

Xray tomographic microscopy at the TOMCAT beam line of SLS at PSI successfully performed earlier on paint chips from Amiet and grounds used by F.E. Church [2] was now applied to an already embedded paint chip that had been hand polished before (Fig. 1). Resin was carefully reduced and the sample was mounted on a 750 micron diameter steel pin with epoxy-glue. Analysis required a $38 \mathrm{keV}$ beam while the sample was cooled with LN to 233 K. Fig. 2 shows its segmented reconstruction using Avizo 6.1 software. The white surface is the surface paint with many mesocracks. The yellow materials are palmierite aggregates and extruded substances through the crack. Wallner line cracks were also observed and could be followed in movie mode through the virtual cross sections (see Fig 3) leading to surface paint that is delaminating and pushed up presumably by temperature or moisture induced shrinkage of the paint. 
[1] Boon, J.J. and Oberthaler, E. (2010). In: Sabine Haag, Elke Oberthaler and Sabine Pénot (Eds.) Vermeer Die Malkunst - Spurensicherung an einem Meisterwerk, exhibition catalogue, Vienna.

[2] Ferreira E.S.B., BoonJ.J., van der Horst J, Scherrer N.C., Marone F., Stampanoni M., (2009). In O3A: Optics for Arts, Architecture, and Archaeology II, edited by Luca

Pezzati, Renzo Salimbeni,Proc. of SPIE Vol. 7391, 73910L · C 2009 SPIE

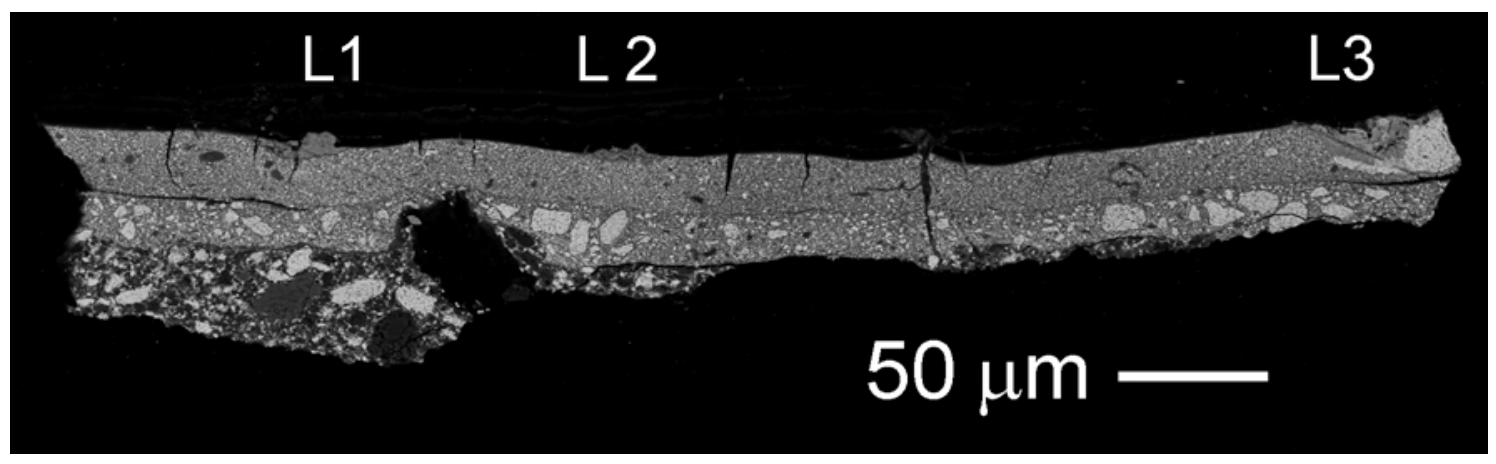

Fig. 1: Back scatter SEM of a paint from a white tile in The Art of Painting. The greyish material at L1, L2 and L3 are palmierite aggregates.

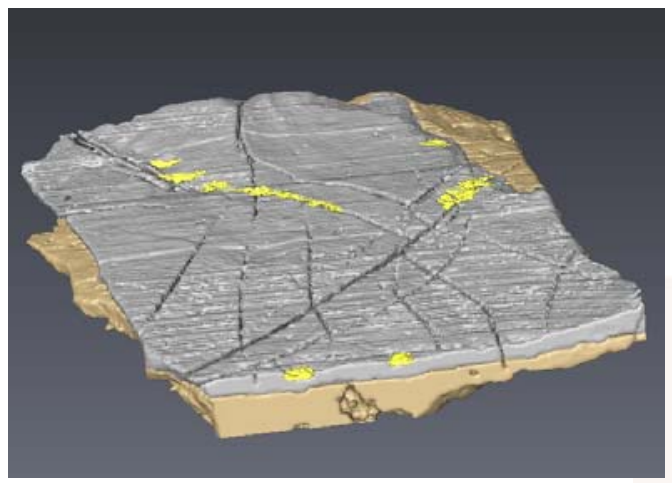

Fig 2: Segmented reconstruction of the paint chip in Fig 1 after Xray tomographic microscopy. Note the extruded materials and reaction products in yellow.

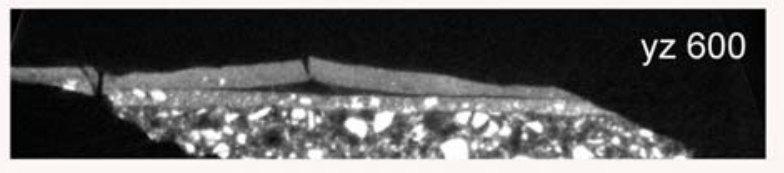

Fig 3: Virtual sections showing conchoidal crack development and delamination of the surface paint layer (15 micron thick). Step size resolution 350 micron.
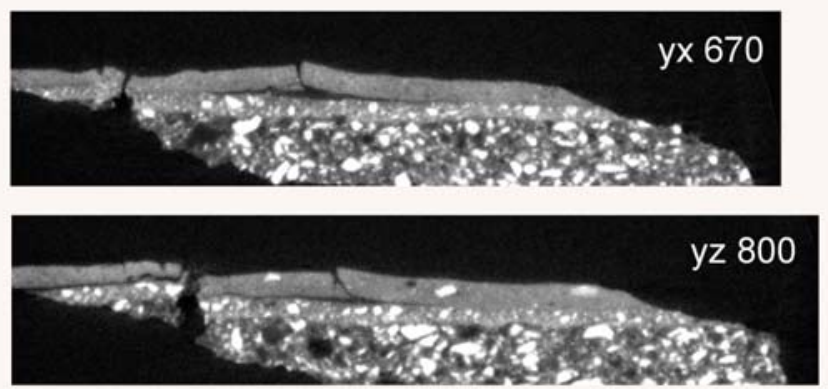